\title{
Tribological Investigation of Graphene as Lubricant Additive in Vegetable Oil
}

\author{
Stephen Sie Kiong Kiu, ${ }^{1}$ Suzana Yusup, ${ }^{1 *}$ Chok Vui Soon, ${ }^{2}$ Taufiq Arpin, ${ }^{2}$ \\ Syahrullail Samion ${ }^{3}$ and Ruzaimah Nik Mohamad Kamil ${ }^{4}$ \\ ${ }^{1}$ Biomass Processing Lab, Center of Biomass and Biofules Research, \\ MOR Green Technology, Chemical Engineering Department, \\ Universiti Teknologi PETRONAS, 32610 Tronoh, Perak, Malaysia \\ ${ }^{2}$ Scomi Platinum Sdn. Bhd, 70450 Seremban, Negeri Sembilan, Malaysia \\ ${ }^{3}$ Faculty of Mechanical Engineering, Universiti Teknologi Malaysia, \\ 81310 UTM Skudai, Johor, Malaysia \\ ${ }^{4}$ Fundamental and Applied Science Department, Universiti Teknologi PETRONAS, \\ 32610 Tronoh, Perak, Malaysia \\ *Corresponding author: drsuzana_yusuf@petronas.com.my
}

Published online: 15 February 2017

To cite this article: Kiu, S. S. K. et al. (2017). Tribological investigation of graphene as lubricant additive in vegetable oil. J. Phys. Sci., 28(Supp. 1), 257-267, https://doi.org/ 10.21315/jps2017.28.s1.17

To link to this article: https://doi.org/10.21315/jps2017.28.s1.17

\begin{abstract}
In this study, the tribological behaviours of graphene nanoparticles as lubricant additive in vegetable oil were investigated as a function of nanoparticle concentration. Graphene nanoparticles were added at $25 \mathrm{ppm}, 50 \mathrm{ppm}$ and $100 \mathrm{ppm}$ as additive into vegetable oil as lubricant through hydrodynamic and acoustic cavitation as homogenising mechanism. The tribological properties of each homogenised solution were tested using a four-ball machine according to ASTM D4172. Wear scar diameter and friction coefficient were the determining parameters in this study. The results showed that $50 \mathrm{ppm}$ is the optimum concentration that recorded the lowest wear scar diameter and friction coefficient as compared to control sample.
\end{abstract}

Keywords: Lubricant additive, hydrodynamic cavitation, coefficient of friction, graphene, vegetable oil 


\section{INTRODUCTION}

Over the past decades, numerous studies have been carried out on the effect of different nanoparticles in lubricant. The five major groups of nanoparticles added to lubricant are metal, ${ }^{1,2}$ metal oxide ${ }^{3,4}$ metal composite, ${ }^{5,6}$ boron-based ${ }^{7,8}$ and carbon-based nanoparticles. ${ }^{9-13}$ In general, the majority of the studies accepted that nanoparticle plays a role in improving tribological properties by forming a tribofilm that is deposited between the contact surfaces. ${ }^{14,15}$ Among all lubricant additives, graphene was chosen as lubricant additive in this study because of its excellent chemical and physical properties such as ultrathin structure, high thermal stability, ultra-smooth surface and ultimate mechanical strength. ${ }^{16}$

Meanwhile, due to increasing awareness among the community of environmental pollution by petroleum-based oils, many researchers had switched their attention to vegetable oil (VO) which is more environmental friendly. Usage of vegetable oil is recommended because it is renewable, biodegradable and nontoxic in nature. It also possesses the properties required for lubrication, including excellent lubricity, high flash point and viscosity index. ${ }^{17}$ Therefore, VO was selected as lubricant in this study.

Over the past years, acoustic cavitation (AC) had been widely preferred for nanoparticle homogenisation process. For instance, Mahbubul et al. demonstrated that $\mathrm{AC}$ managed to produce better particle dispersion, smaller aggregate sizes, and higher zeta potential after dispersing $\mathrm{Al}_{2} \mathrm{O}_{3}$ nanofluid using ultrasonic horn for $3 \mathrm{~h} .{ }^{18}$ Besides, Arumugam and Sriram also agitated their $\mathrm{TiO}_{2}$ nanofluid by using $\mathrm{AC}$ at room temperature for $3 \mathrm{~h}$ to ensure uniform dispersion and good suspensions stability. ${ }^{19}$

Meanwhile, Yu et al. prepared AIN-ethylene glycol and AIN-propylene glycol nanofluids by using stirring and $\mathrm{AC}$ for $3 \mathrm{~h}$. Their results showed that average particle sizes of their nanofluids was $165-169 \mathrm{~nm} .{ }^{20}$ Meanwhile, hydrodynamic cavitation which exhibited similar effect as acoustic cavitation ${ }^{21}$ was commonly used to intensify various physical/chemical process operations. ${ }^{22}$ Both cavitations underwent three steps, which are bubble generation, bubble collapse and energy release. The collapse of bubbles created high energy release that can effectively break the cluster of nanaoparticles and assist in deagglomeration process of particle clusters ${ }^{23}$ The difference between acoustic and hydrodynamic cavitation was shown in Table 1. 
Table 1: Differences between acoustic cavitation and hydrodynamic cavitation.

\begin{tabular}{lll}
\hline Type of cavitation & Acoustic cavitation & Hydrodynamic Cavitation \\
\hline $\begin{array}{l}\text { Mechanism to } \\
\text { generate cavities }\end{array}$ & $\begin{array}{l}\text { Cavitation is formed by pressure } \\
\text { variations in the liquid which are } \\
\text { induced by using sound waves } \\
(16 \mathrm{KHz}-100 \mathrm{MHz})\end{array}$ & $\begin{array}{l}\text { Cavitation is produced by pressure } \\
\text { variations which is obtained using } \\
\text { geometry of the system creating } \\
\text { velocity variation }\end{array}$ \\
Operation & $\begin{array}{l}\text { Set frequency and duration } \\
\text { for ultrasonic wave, by using } \\
\text { ultrasonicator probe or } \\
\text { ultrasonic bath }\end{array}$ & $\begin{array}{l}\text { Controlling flow rate and pressure } \\
\text { drop by using venturi or orifice } \\
\text { plate }\end{array}$ \\
& $\begin{array}{l}\text { Cheaper, set-up is simple, } \\
\text { easy to control and monitor }\end{array}$ & Energy efficient, easy to scale up \\
Benefits & & \\
\hline
\end{tabular}

However, to the extent of authors' knowledge, not much study had been carried out on hydrodynamic cavitation homogenisation process. There has been few to no literature reported on the combination of both $\mathrm{AC}$ and $\mathrm{HC}$ method for the homogenisation of nanoparticles. Therefore, in this study the authors explore the homogenisation process by using a combination of hydrodynamic cavitation and acoustic cavitation method.

\section{EXPERIMENTAL}

\subsection{Materials}

Graphene nanosheet powder and vegetable oil were provided by Scomi Platinum Sdn. Bhd., a local company which manufactures high performance chemical products. The physical properties of nanosheets were shown in Table 2 below.

Table 2: Physical properties of graphene nanosheets.

\begin{tabular}{lc}
\hline Physical Properties & Value \\
\hline Density & 0.23 \\
Carbon Content $(\%)$ & $67-75$ \\
X-Y Dimensions $(\mu \mathrm{m})$ & $0.06-0.1$ \\
Z Dimension $(\mu \mathrm{m})$ & $0.005-0.01$ \\
Oxygen $(\%)$ & $25-35$ \\
BET surface area $\left(\mathrm{m}^{2} / \mathrm{gm}\right)$ & 150 \\
\hline
\end{tabular}




\subsection{Lubricants}

In this study, oil palm based VO was used as lubricant. VO was provided by Scomi Platinum Sdn. Bhd. The physical properties of VO were shown in Table 3.

Table 3: Physical properties of VO.

\begin{tabular}{|c|c|c|}
\hline Physical Properties & Value & Method \\
\hline Pour Point & $-24^{\circ} \mathrm{C}$ & ISO 3016: Determination of pour point \\
\hline Flash Point & $235^{\circ} \mathrm{C}$ & $\begin{array}{l}\text { ISO 2592: Determination of flash and fire points- } \\
\text { Cleveland open cup method }\end{array}$ \\
\hline Density & $886 \mathrm{~kg} / \mathrm{m}^{3}$ & $\begin{array}{l}\text { ISO 12185: Crude petroleum and petroleum } \\
\text { products- Determination of density- Oscillating } \\
\text { U-tube method }\end{array}$ \\
\hline Kinematic viscosity & $\begin{array}{c}68 \mathrm{~mm}^{2} / \mathrm{s}\left(40^{\circ} \mathrm{C}\right) \\
1040 \mathrm{~mm}^{2} / \mathrm{s}\left(0^{\circ} \mathrm{C}\right) \\
8.6 \mathrm{~mm}^{2} / \mathrm{s}\left(100^{\circ} \mathrm{C}\right)\end{array}$ & $\begin{array}{l}\text { ASTM D445-06 } \\
\text { Standard Test Method for Kinematic Viscosity of } \\
\text { Transparent and Opaque Liquids }\end{array}$ \\
\hline
\end{tabular}

\subsection{Experiment Apparatus}

The experiment setup was illustrated in Figure 1. It consists of a hydrodynamic cavitation unit, pressure gauge, pressure pump and a stirrer.

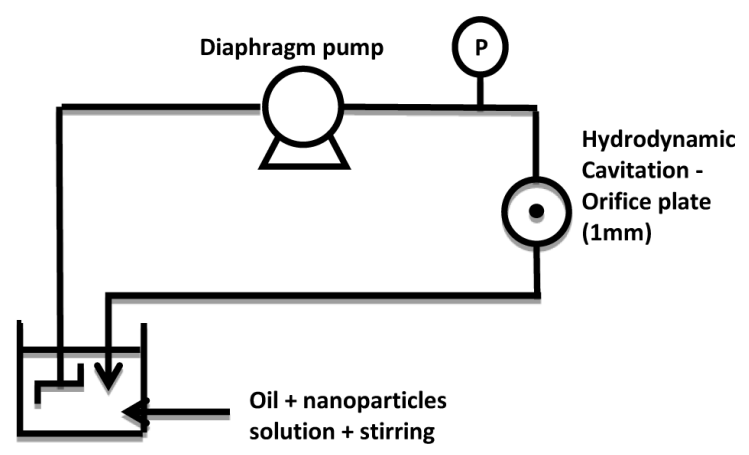

Figure 1: Schematic diagram of experiment setup of hydrodynamic cavitation unit.

\subsection{Experiment Procedure}

Graphene nanosheets were added to $\mathrm{VO}$ at $25 \mathrm{ppm}, 50 \mathrm{ppm}$ and $100 \mathrm{ppm}$ respectively and homogenised using acoustic cavitation and hydrodynamic cavitation. Three graphene nanofluid samples at different concentrations were prepared in this study. Orifice plate with internal diameter of $1 \mathrm{~mm}$ was used in 
the hydrodyanamic cavitation unit. Each sample was circulated in $\mathrm{HC}$ unit for $1 \mathrm{~h}$ followed by acoustic cavitation using Brandon $8510 \mathrm{E}$ Ultrasonicator, at $320 \mathrm{~W}$ and $40 \mathrm{kHz}$ for $1 \mathrm{~h}$. A stirrer was inserted into the storage tank and operated continuously at $300 \mathrm{rpm}$ to mix continuously. The pressure pump was operated at flow rate of $1.5 \mathrm{~m} / \mathrm{s}$, orifice pressure of $10 \mathrm{bar}$, with open-ended tank of atmospheric pressure.

\subsection{Four-ball Test}

VO and three prepared nanofluids were tested under ASTM D4172 Wear Preventive Characteristics of Lubricating Fluid (Four-Ball Method) using DUCOM four-ball tribotester. Four-ball test is a standard test used to determine the relative wear preventive properties and load bearing capacity of lubricating fluids in sliding contact under the prescribed test conditions. Four-ball test was also used by Syahrullail et al. to measure the friction coefficient value and wear scar diameter produced by pure mineral oil and mixture of palm oil in mineral oil. ${ }^{24}$ Zhao et al. also utilised four-ball test incorporated with pin on disc tester to study the effect of zinc borate as lubricant additive in sunflower oil..$^{25}$

In the four-ball test, three $12.7 \mathrm{~mm}$ diameter steel balls were clamped together and covered with the lubricant to be evaluated as shown in Figure 2. ${ }^{26}$ By rotating the top ball against three bottom ball at operating condition of $1200 \mathrm{rpm}, 75^{\circ} \mathrm{C}, 392 \mathrm{~N}$ for $1 \mathrm{~h}$, wear scar will be produced on the contact surfaces on balls, and the average coefficient of friction between the contact surface was recorded using software, Winducom 2010. The setup of four ball tribotester was described by Ing et al. ${ }^{27}$

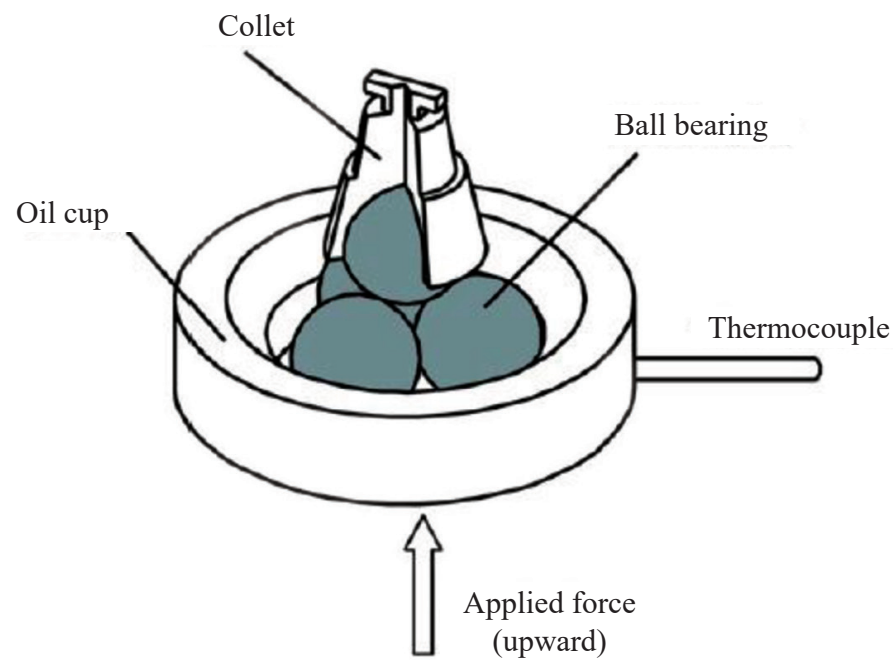

Figure 2: Schematic diagram of four balls set up in the experiment. 


\subsection{Wear Scar Diameter}

After each four ball-test, wear scar was produced on the surface of the steel balls. The wear scar produced on each used ball was observed under an optical microscope attached with computer. With the aid of dimension software, the image of the wear was captured and its diameter was measured as shown in Figure 3. In the four-ball test, the wear scar is measured in a single direction where the average reading of wear scar diameters produced at each ball respectively was calculated and recorded.

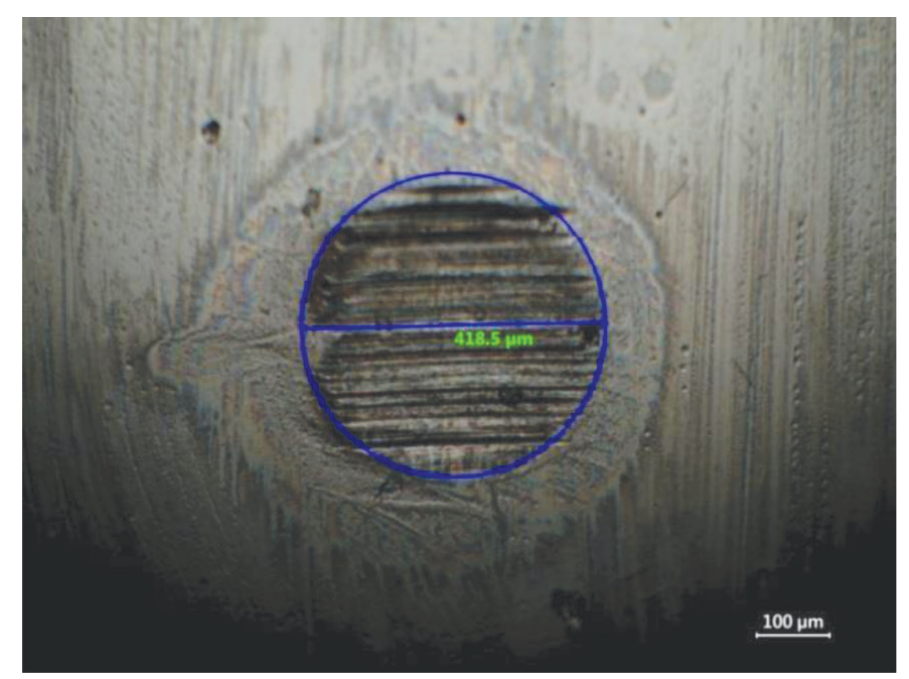

Figure 3: Wear scar diameter measured on one of the used balls.

\section{RESULTS AND DISCUSSION}

\subsection{Suspension Stability}

Figure 4(a) shows that graphene powders floated temporary in VO after mixing through acoustic and hydrodynamic cavitation. Graphene powders eventually settle when left undisturbed for $24 \mathrm{~h}$ as shown in Figure 4(b). 

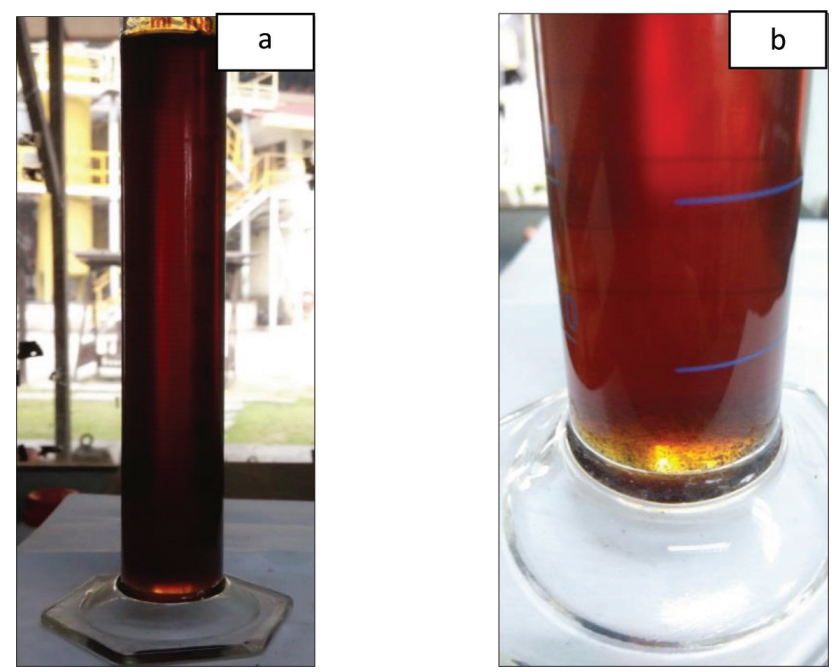

Figure 4: Illustration of (a) homogenised graphene nanofluid at 100ppm after cavitation; and (b) remarkable graphene sediments after left undisturbed for $24 \mathrm{~h}$.

The aggregate size of nanoparticles agglomerates was estimated by using Stoke's sedimentation formula ${ }^{28}$ as below:

$$
T=\frac{9 l \mu}{2 r^{2}\left(\rho_{p}-\rho_{s}\right) g}
$$

where,

$l=$ height of the nanofluid $(\mathrm{m})$,

$\mu=$ dynamic viscosity of oil (kg/m.s),

$\rho_{p}=$ particle density,

$\rho_{s}=$ Liquid density $\left(\mathrm{kg} / \mathrm{m}^{3}\right)$,

$\mathrm{G}=$ gravitational constant $\left(\mathrm{m} / \mathrm{s}^{2}\right)$, and

$\mathrm{T}=$ settlement period $(\mathrm{s})$

By substituting the parameters into the equation, the estimated radius of agglomerates size achieved is $1.5 \times 10^{-4} \mathrm{~m}$. From this result, it was proven that the nanoparticles had agglomerated into larger agglomerates which in turn caused poor suspension stability. Due to limited stability of graphene added VO nanofluids, 25 ppm, 50 ppm and 100 ppm graphene nanofluids were directly sent for four-ball test after mixing. 


\subsection{Friction Coefficient and Wear Scar Diameter}

Figures 5 and 6 show the trend of friction coefficient (COF) and wear scar diameter (WSD) with respect to increment of graphene concentration at $25 \mathrm{ppm}$, $50 \mathrm{ppm}$ and $100 \mathrm{ppm}$. Both COF and WSD decrease with increasing graphene concentration until $50 \mathrm{ppm}$, further increment to $100 \mathrm{ppm}$ of graphene leads to remarkable increase in friction coefficient and wear, even higher than pure VO. Since graphene nanosheets have a planar structure, they can slide easily between the contact surfaces and sliding can help reduce friction between contact surfaces. However, addition of overloaded graphene resulted in aggregation and stacking, leading to increment in wear and friction between the surfaces.

\section{Friction Coefficient against Concentration of Graphene}

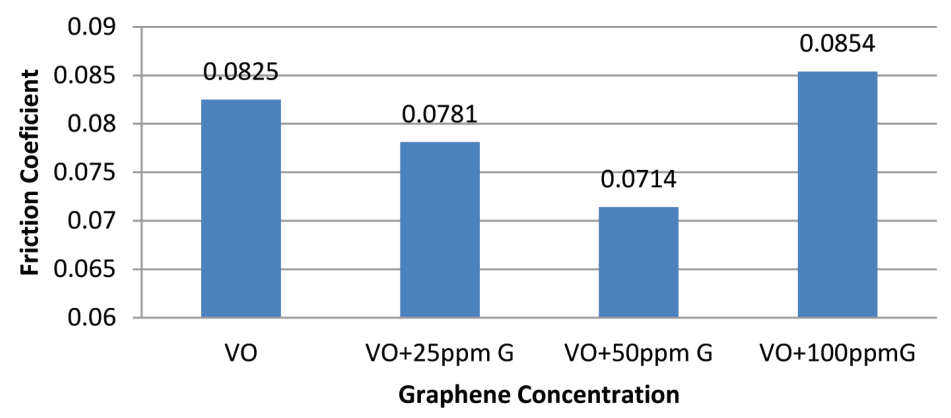

Figure 5: Friction coefficient of $\mathrm{VO}, \mathrm{VO}+25 \mathrm{ppmG}, \mathrm{VO}+50 \mathrm{ppmG}$, and $\mathrm{VO}+100$ ppmG.

\section{Wear Scar Diameter against} Concentration of Graphene

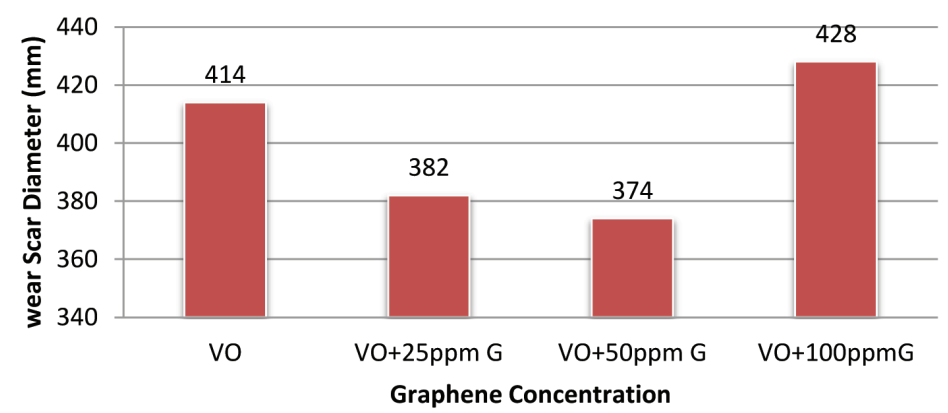

Figure 6: Wear scar diameter of $\mathrm{VO}, \mathrm{VO}+25 \mathrm{ppmG}, \mathrm{VO}+50 \mathrm{ppmG}$ and $\mathrm{VO}+100 \mathrm{ppmG}$. 
Similarly, Eswaraiah et al. found that by adding optimum amount of $0.025 \mathrm{wt} \%$ graphene, lowest COF and WSD were recorded. ${ }^{29}$ In their study, initially COF and WSD decrease with increasing graphene concentration until its optimum concentration is reached. Further increment in graphene concentration also leads to detrimental impact towards lubricating properties. Therefore, addition of 50 ppm graphene into $\mathrm{VO}$ is the optimum concentration recommended in this study.

\section{CONCLUSION}

In conclusion, addition of graphene into vegetable oil showed improvement in tribological properties by reducing friction coefficient and wear scar diameter. The results showed that $25 \mathrm{ppm}$ and $50 \mathrm{ppm}$ graphene can reduce friction coefficient and wear scar diameter as compared to pure VO. However, addition of up to 100 ppm resulted in aggregation and stacking, thus leading to higher friction and wear as compared to pure VO. Therefore, addition of $50 \mathrm{ppm}$ is recommended as optimum concentration for VO based on this study. However, suspensions stability of graphene in VO only lasted for $24 \mathrm{~h}$. Hence, surface modification of graphene can be proposed as future work to improve its miscibility with VO. Also, future works involving synthesis and characterisation of graphene are needed to have better understanding on its surface which is the key to understand its tribological properties.

\section{ACKNOWLEDGEMENT}

The authors wish to thank Scomi Sdn. Bhd. and the Mechanical Department, Universiti Teknologi Malaysia for their support during this study. This work was supported by the BIOMASS Grant (0153AB-F02).

\section{REFERENCES}

1. Choi, Y. et al. (2009). Tribological behavior of copper nanoparticles as additives in oil. Curr. Appl. Phys., 9(2), 124-127, https://doi.org/10.1016/j. cap.2008.12.050.

2. Zhang, S. et al. (2013). Anti-wear and friction-reduction mechanism of $\mathrm{Sn}$ and $\mathrm{Fe}$ nanoparticles as additives of multialkylated cyclopentanes under vacuum condition. Vacuum, 87, 75-80, https://doi.org/10.1016/j. vacuum.2012.07.009. 
3. Hernandez Battez, A. et al. (2008). $\mathrm{CuO}, \mathrm{ZrO} 2$ and $\mathrm{ZnO}$ nanoparticles as antiwear additive in oil lubricants. Wear, 265(3-4), 422-428, https://doi. org/10.1016/j.wear.2007.11.013.

4. Luo, T. et al. (2014). Tribological properties of Al2O3 nanoparticles as lubricating oil additives. Ceram. Int., 40(5), 7143-7149, https://doi. org/10.1016/j.ceramint.2013.12.050.

5. Luo, T. et al. (2014). Tribology properties of $\mathrm{Al} 2 \mathrm{O} 3 / \mathrm{TiO} 2$ nanocomposites as lubricant additives. Ceram. Int., 40(7), 10103-10109, https://doi. org/10.1016/j.ceramint.2014.03.181.

6. Zhang, C. et al. (2014). Preparation and tribological properties of watersoluble copper/silica nanocomposite as a water-based lubricant additive. Tribol. Lett., 54(1), 25-33, https://doi.org/10.1007/s11249-014-0304-5.

7. Yan, J. et al. (2014). The tribological performance and tribochemical analysis of novel borate esters as lubricant additives in rapeseed oil. Tribol. Int., 71, 149-157, https://doi.org/10.1016/j.triboint.2013.10.009.

8. Wan, Q. et al. (2015). Tribological behaviour of a lubricant oil containing boron nitride nanoparticles. Proced. Eng., 102, 1038-1045, https://doi. org/10.1016/j.proeng.2015.01.226.

9. Zhao, J. et al. (2016). An investigation on the tribological properties of multilayer graphene and MoS2 nanosheets as additives used in hydraulic applications. Tribol. Int., 97, 14-20, https://doi.org/10.1016/j. triboint.2015.12.006.

10. Nunn, N. et al. (2015). Tribological properties of polyalphaolefin oil modified with nanocarbon additives. Diam. Relat. Mater., 54(1), 97-102, https://doi.org/10.1016/j.diamond.2014.09.003.

11. Kinoshita, H. et al. (2014). Tribological properties of monolayer graphene oxide sheets as water-based lubricant additives. Carbon N. Y., 66, 720-723, https://doi.org/10.1016/j.carbon.2013.08.045.

12. Fan, X. \& Wang, L. (2015). Ionic liquids gels with in situ modified multiwall carbon nanotubes towards high-performance lubricants. Tribol. Int., 88, 179-188, https://doi.org/10.1016/j.triboint.2015.03.026.

13. Antonio, J. et al. (2015). Tribological properties of carbon nanotubes as lubricant additive in oil and water for a wheel-rail system. Integr. Med. Res., $5(1), 68-76$.

14. Li, J. et al. (2015). Tribological study and mechanism of B-N and B-S-N triazine borate esters as lubricant additives in mineral oil. Tribol. Int., 88, 1-7, https://doi.org/10.1016/j.triboint.2015.03.002.

15. Nan, F. et al. (2015). Tribological behaviors and wear mechanisms of ultrafine magnesium aluminum silicate powders as lubricant additive. Tribol. Int., 81(21), 199-208, https://doi.org/10.1016/j.triboint.2014.09.006. 
16. Zhang, L. et al. (2016). Preparation and tribological properties of novel boehmite/graphene oxide nano-hybrid. Ceram. Int., 42(5), 6178-6186, https://doi.org/10.1016/j.ceramint.2015.12.178.

17. Stok, P. et al. (2013). Synthesis of rubber seed oil and trimethylolpropane based biolubricant base stocks. Msian J. Anal. Sci., 17(3), 414-421.

18. Mahbubul, I. M. et al. (2015). Effective ultrasonication process for better colloidal dispersion of nanofluid. Ultrason. Sonochem., 26, 361-369, https://doi.org/10.1016/j.ultsonch.2015.01.005.

19. Arumugam, S. \& Sriram, G. (2013). Preliminary study of nano- and microscale tio 2 additives on tribological behavior of chemically modified rapeseed oil. Tribol. Trans., 56(5), 797-805, https://doi.org/10.1080/10402 004.2013.792977.

20. Yu, W. et al. (2011). Particuology experimental investigation on thermal conductivity and viscosity of aluminum nitride nanofluid. Particuology, 9(2), 187-191, https://doi.org/10.1016/j.partic.2010.05.014.

21. Moholkar, V. S. et al. (1999). Hydrodynamic cavitation for sonochemical effects. Ultrason. Sonochem., 6(1-2), 53-65, https://doi.org/10.1016/S13504177(98)00030-3.

22. Gogate, P. R. \& Pandit, A. B. (2001). Hydrodynamic cavitation reactors: A state of the art review. Rev. Chem. Eng., 17, 1-85, https://doi.org/10.1515/ REVCE.2001.17.1.1.

23. Hwang, Y. et al. (2008). Production and dispersion stability of nanoparticles in nanofluids. Powder Technol., 186, 145-153, https://doi.org/10.1016/j. powtec.2007.11.020.

24. Syahrullail, S. et al. (2013). Friction characteristic of mineral oil containing palm fatty acid distillate using four ball tribo-tester. Procedia Eng., 68, 166171, https://doi.org/10.1016/j.proeng.2013.12.163.

25. Zhao, C. L. et al. (2014). The tribological properties of zinc borate ultrafine powder as a lubricant additive in sunflower oil. Tribol. Trans., 57(3), 425434, https://doi.org/10.1080/10402004.2013.878776.

26. Ing, T. C. et al. (2012). Tribological behaviour of refined bleached and deodorized palm olein in different loads using a four-ball tribotester. Sci. Iran., 19(6), 1487-1492, https://doi.org/10.1016/j.scient.2012.10.027.

27. Ing, T. C., Rafiq, M. \& Kadir, A. (2011). Experimental evaluation on lubricity of RBD palm olein using fourball tribotester. Tribol. Lubr. Lubr., 175-185.

28. Zheng, L. et al. (2013). Sedimentation and precipitation of nanoparticles in power-law fluids. Microfl. Nanofl., 15, 11-18, https://doi.org/10.1007/ s10404-012-1117-1.

29. Eswaraiah, V. Sankaranarayanan, V. \& Ramaprabhu, S. (2011). Graphenebased engine oil nanofluids for tribological applications. ACS Appl. Mater. Interf., 3(11), 4221-4227, https://doi.org/10.1021/am200851z. 
